Sonic Scope: New Approaches to Audiovisual Culture •

\title{
I'm Not The Sentimental Type - Mathew Lomas
}

Mathew Lomas

Published on: Oct 29, 2021

DOI: 10.21428/66f840a4.c8a79825

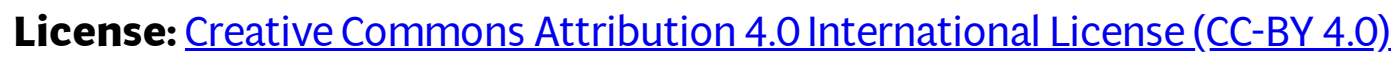




\section{I'm Not The Sentimental Type}

Mathew Lomas, Goldsmiths, University of London

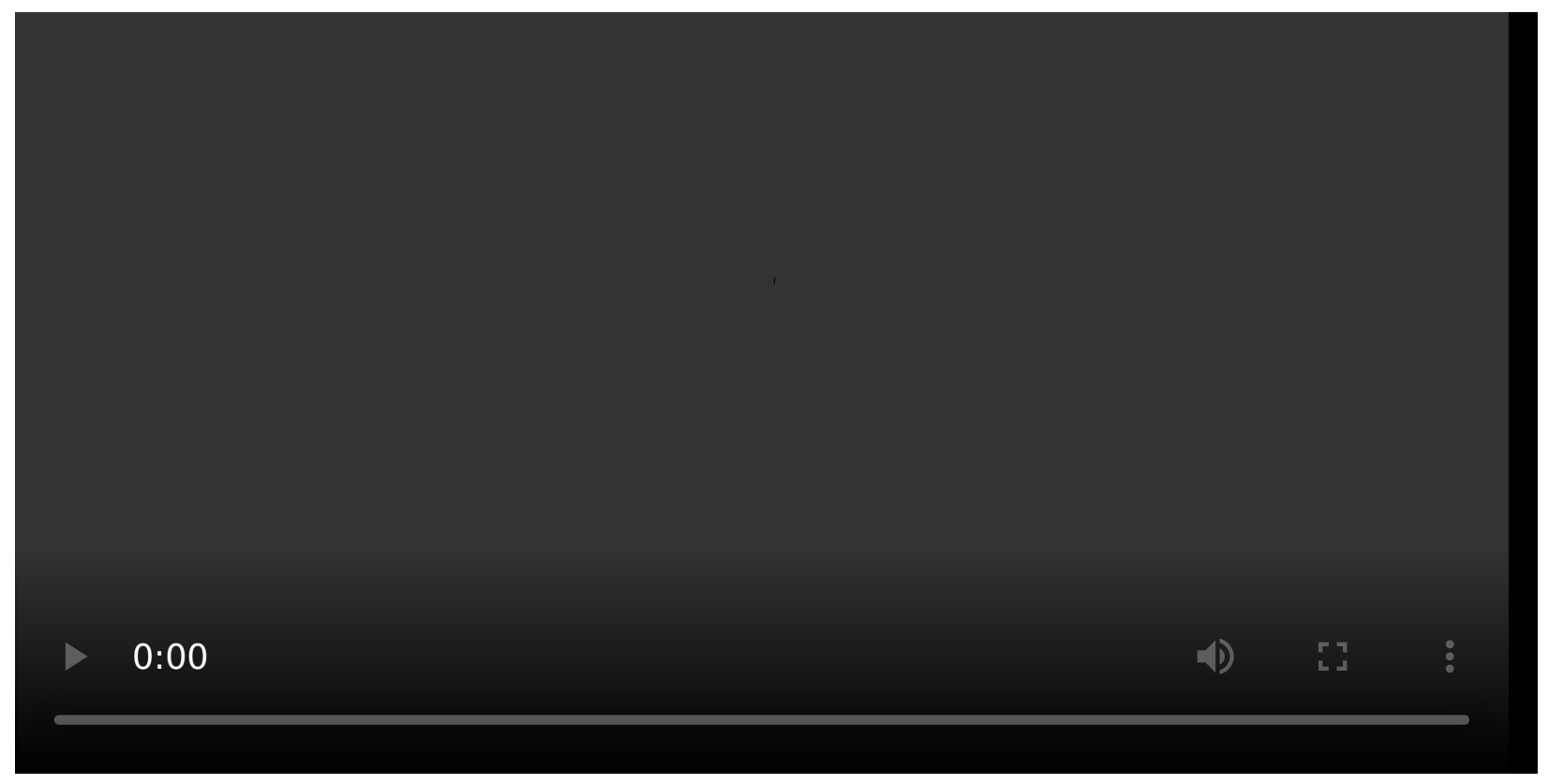

